\title{
Automatic Target Recognition (ATR) from SAR Imaginary by Using Machine Learning Techniques
}

\author{
Umut Özkaya ${ }^{* 1}$ \\ 1* Department of Electrical Electronics Engineering, Engineering Faculty, Konya Technical University, Konya, Turkey (ORCID: 0000-0002-9244-0024)
}

$\left(1^{\text {st }}\right.$ International Conference on Computer, Electrical and Electronic Sciences ICCEES 2020 - 8-10 October 2020)

(DOI: $10.31590 /$ ejosat.802811)

ATIF/REFERENCE: Özkaya, U. (2020). Automatic Target Recognition (ATR) from SAR Imaginary by Using Machine Learning Techniques. European Journal of Science and Technology, (Special Issue), 165-169.

\begin{abstract}
Automatic Target Recognition (ATR) in Synthetic aperture radar (SAR) images becomes a very challenging problem owing to containing high level noise. In this study, a machine learning-based method is proposed to detect different moving and stationary targets using SAR images. First Order Statistical (FOS) features were obtained from Fast Fourier Transform (FFT), Discrete Cosine Transform (DCT) and Discrete Wavelet Transform (DWT) on gray level SAR images. Gray Level Co-occurrence Matrix (GLCM), Gray Level Run Length Matrix (GLRLM) and Gray Level Size Zone Matrix (GLSZM) algorithms are also used. These features are provided as input for the training and testing stage Support Vector Machine (SVM) model with Gaussian kernels. 4-fold crossvalidations were implemented in performance evaluation. Obtained results showed that GLCM + SVM algorithm is the best model with $95.26 \%$ accuracy. This proposed method shows that moving and stationary targets in MSTAR database could be recognized with high performance.
\end{abstract}

Keywords: SAR, Target Recognition, Machine Learning, Feature Extraction, Support Vector Machine.

\section{Makine Öğrenimi Tekniklerini Kullanarak SAR Görüntülemesinden Otomatik Hedef Tanıma (OHT)}

$\ddot{O} z$

Sentetik açıklıklı radar (SAR) görüntülerinde Otomatik Hedef Tanıma (OHT), içerdiği yüksek seviyeli gürültü nedeniyle çözümü çok zor bir sorun haline gelmiştir. Bu çalışmada, SAR görüntülerini kullanarak farklı hareketli ve sabit hedefleri tespit etmek için makine öğrenmesine dayalı bir yöntem önerilmiștir. Birinci Derece İstatistik (BDİ) özellikleri, gri seviyedeki SAR görüntülerinde Hızlı Fourier Dönüşümü (HFD), Ayrık Kosinüs Dönüşümü (AKD) ve Ayrık Dalgacık Dönüşümü (ADD) uygulandıktan sonra elde edilmiştir. Gri Seviye Eş Oluşum Matrisi (GSEOM), Gri Seviye Çalışma Uzunluğu Matrisi (GSÇUM) ve Gri Seviye Boyutu Bölge Matrisi (GSBBM) algoritmaları da özellik elde edilmesi için kullanılmaktadır. Bu özellikler, eğitim ve test aşaması için Gaussian çekirdeklere sahip Destek Vektör Makinesi (DVM) modeli için girdi olarak verilmiştir. Performans değerlendirmesinde 4 katlı çapraz doğrulama yapılmıştır. Elde edilen sonuçlar, GSEOM + DVM algoritmasının \% 95.26 doğrulukla en iyi model olduğunu göstermiş̧ir. Önerilen bu yöntem, MSTAR veri tabanındaki hareketli ve sabit hedeflerin yüksek performansla tanınabileceğini göstermektedir.

Anahtar Kelimeler: SAR, Hedef Tanıma, Makine Öğrenmesi, Özellik Çıkarımı, Destek Vektör Makinesi

\section{Introduction}

Synthetic aperture radar (SAR) is a device to obtain images in full time and actively (Quan et al. 2018). SAR images are frequently used in reconnaissance, surveillance, target recognition and tracking for military application (Dong et al. 2017). In recent years, recognition and detection of targets in SAR images has been increased to study day by day. Target recognition in SAR images a challenging task owing to including high level noise. Automatic Target Recognition (ATR) process, which is planned to be performed on SAR images, has two stages. First of all, external factors, which are trees, cars, buildings, etc, reveal the false alarm situation. It is 
necessary to be omitted these from images. In the second stage, it performs feature extraction and classification algorithms (O'Sullivan et al. 2001).

Template matching technique, one of the traditional methods, is inadequate in target detection. The main reason for this is that there are changes in targets on SAR images due to the noise level (Novak et al. 1993). In some studies, it has been tried to recognize the targets by obtaining local and global features (Jianxiong et al 2011). Dong et al. obtained sparse representations of SAR images and recognize targets with different classifiers (Dong et al. 2015). Pan et al. carried out a multiscale feature fusion by performing canonical correlation analysis of sparse matrices. The fused features were classified for target recognition in SAR images (Pan et al. 2016). Liu et al. obtained features from SAR images. These were evaluated from two different classifiers and classification results were fused (Liu et al. 2013).

ATR operation on SAR images is observed as an ongoing problem. Raw SAR images include serious challenges. Obtaining SAR images is one of the most important problem. It also contains a high amount of noise in SAR images. Moving and Stationary Target Acquisition and Recognition (MSTAR) dataset is frequently used for ATR operations (Liu and Li, 2013). Novak et al. achieved 66.2\% and 77.4\% accuracy for 20-class and 10-class in the MSTAR data set respectively (Novak et al. 1998). Martone et al. used k-means clustering algorithm for detection of moving targets in forested land (Martone et al 2009). Gorovyi and Sharapov achieved an accuracy rate of $90.7 \%$ with SVM on the MSTAR data set (Gorovyi and Sharapov 2017).

In this study, MSTAR data set was used. SAR images with 150 degrees in the data set were used for both training and testing in classification algorithm. Two different strategies were followed for methodology. Fast Fourier Transform (FFT), Discrete Cosine Transform (DCT) and Discrete Wavelet Transform (DWT) were applied to gray level SAR images. First Order Statistical (FOS) features were obtained from these transformation matrices. These features were classified with Support Vector Machine algorithm with Gaussian Kernels. Another strategy is to use gray level feature extraction methods. These methods are respectively Gray Level Co-occurrence Matrix (GLCM), Gray Level Run Length Matrix (GLRLM) and Gray Level Size Zone Matrix (GLSZM). The obtained features are processed in SVM with Gaussian kernels. This paper is organized as follows. Section 2 includes materials and methods. Section 3 presents findings and discussion. Section 4 is conclusion part.

\section{Material and Method}

\subsection{Dataset Description}

The data set used in the study was named as MSTAR. It was obtained by Defence Advanced Research Projects Agency (DARPA) and the American Air Force Research Laboratory (AFRL) (Singleton 1968). SAR data were collected at different angles with the help of a radar operating in X band. In this study, analyses were performed on SAR images of 2S1, BRDM-2, BTR-60, D7, SLICY, T62, ZIL 131 and ZSU-23-4. Optical and SAR images of these classes are shown in Fig. 1.
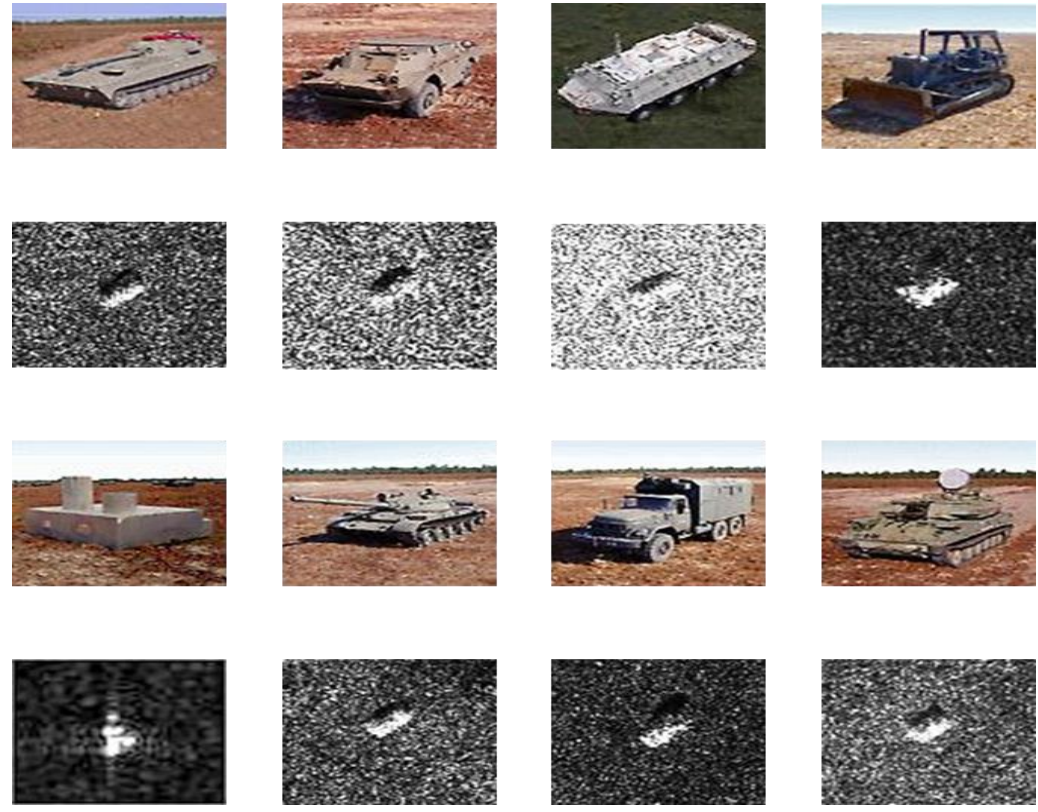

Fig. 1 The examples of 2S1, BRDM-2, BTR-60, D7, SLICY, T62, ZIL 131 and ZSU-23-4 with optical and SAR images

\subsection{Transformation Techniques}

Discrete Fourier Transforms (DFT) converts a sequence in time space into an equivalent sequence in frequency space. FFT is a very efficient method based on DFT and requires much less computational load than DFT. FFT is widely used for frequency spectrum analysis in digital signal processing applications (Solomon and Breckon 2011). DCT is a common method in image compression. It is a method similar to DCT and it is a linear transformation. (Eltoukhy et al. 2012). DWT is a filter bank that separates the image into frequency sub-bands (Soh and Tsatsoulis 1999). Where horizontal details refer to horizontal high frequencies, vertical details to vertical high frequencies, diagonal details to high frequencies in both directions. The features were obtained by using LL, LH, HL and 
HH coefficients from DWT. Six features were extracted from each coefficient as mean, variance, kurtosis, skewness, entropy and energy.

\subsection{Transformation Techniques}

GLCM is a feature set consisting of second order statistical features. GLCM is created by considering the relationships between the pixels of an image from different angles. Covariance matrices obtained from an image can be expressed as $P=[p(i, j \mid d, \Theta)]$. Where i. pixel frequency properties and $\mathrm{j}$ are used to evaluate frequency features of neighbouring pixels with reference to $\mathrm{d}$ distance and $\Theta$ direction. GLCM features can be defined as angular second moment, contrast, correlation, sum of squares of variance, inverse moment of difference, total mean, total variance, total entropy, entropy, difference of variance, entropy difference, correlation information criterion 1, correlation information criterion 2, autocorrelation, dissimilarity, cluster tone, cluster prominence, maximum probability, and inverse difference.

GLRLM is a method of extracting high level texture features. Where $\mathrm{G}$ represents the number of gray levels, $\mathrm{R}$ is the longest run $\mathrm{W}$ the number of pixels in the image. GLRLM matrix is in $\mathrm{G} \times \mathrm{R}$ dimension. Each $\mathrm{p}(\mathrm{i}, \mathrm{j} \mid \theta)$ element gives the number of occurrences in the $\theta$ direction at the $i$ gray level and $j$ run length. Seven different statistical features are obtained as short run emphasis, long run emphasis, gray level irregularity, run length irregularity, running percentage, low gray level running emphasis and high gray level running emphasis. GLSZM is a feature extraction technique that has added two new features to GLCM method as size and density of a texture in the image (Thibault et al. 2013).

\subsection{Support Vector Machine}

SVM is a method of achieving high performance in many applications. SVM is based on two key views. . The first idea is to map high dimensional space in a nonlinear method. It makes using of class classifiers in this new space. The second view is to find appropriate hyperplane that separates the data by a large margin. This plane separates the data as well as possible between an infinite numbers of planes (Kulkarni et al. 2011).

\subsection{Proposed Frameworks}

This study includes two different strategies to classify SAR images. In the first strategy, some transformation techniques were applied on SAR images. Then, FOS features were extracted. The second strategy based on gray level features extraction. At last, SVM was performed on these features to classify for ATR. Proposed frameworks are given in Fig. 2.

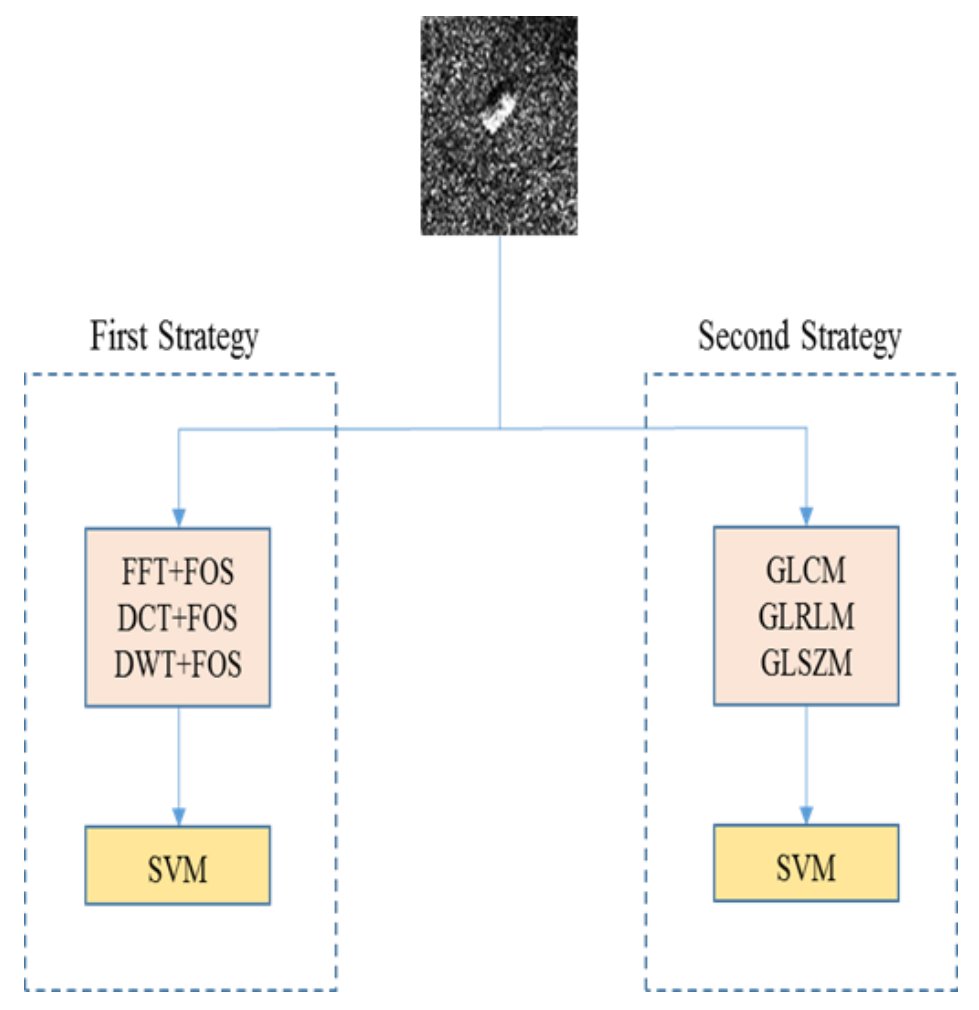

Fig. 2 Proposed Frameworks

\section{Results and Discussion}

In this study, transformation techniques and gray level feature extraction algorithms were used. Classification process was carried out with SVM, which is one of the machine learning methods. Training and testing of SVM classifier was carried out using SAR images in $15^{\circ}$ degree from the MSTAR database. SAR image in $15^{\circ}$ degree numbers for each class are given in Table 1. 
Table 1. Number of SAR Images for Each Classes

\begin{tabular}{|c|c|}
\hline Class & Number of Images \\
\hline 2S1 & 274 \\
\hline BRDM-2 & 274 \\
\hline BTR-60 & 195 \\
\hline D7 & 274 \\
\hline SLICY & 274 \\
\hline T62 & 273 \\
\hline ZIL 131 & 274 \\
\hline ZSU-23-4 & 274 \\
\hline Total & 2112 \\
\hline
\end{tabular}

Six different classification metrics were used to evaluate the proposed feature extraction and performance of SVM model. These metrics are Accuracy (ACC), Precision (SEN), Specificity (SPE), F1-Score, Matthews Correlation Coefficient (MCC). They are given in Eq. 1-6.

$$
\begin{gathered}
\text { Accuracy }=(T P+T N) /(T P+F N+T N+F P) \\
\text { Sensitivity }=T P /(T P+F N) \\
\text { Specificity }=T N /(T N+F P) \\
\text { Precision }=T P /(T P+F P) \\
F 1-\text { Score }=(2 \times T P) /(2 \times T P+F N+F P) \\
M C C=\frac{\mathrm{TP} \times \mathrm{TN}-\mathrm{FP} \times \mathrm{FN}}{\sqrt{(T P+F P)(T P+F N)(T N+F P)(T N+F N)}}
\end{gathered}
$$

Where TP is True Positive, TN is True Negative, FP is False Positive and FN is False Negative. Mean pf metric performances and standard deviations of the proposed methods are given in Table 2.

Table 2. Performance of Proposed Frameworks

\begin{tabular}{|c|c|c|c|c|c|c|}
\hline \multirow{2}{*}{ Methods } & \multicolumn{5}{|c|}{ Evaluation Metrics (\%) } \\
\cline { 2 - 7 } & SEN & SPE & ACC & PRE & F1-Score & MCC \\
\hline FOS+SVM & $74.41 \pm 0.72$ & $96.64 \pm 0.10$ & $76.60 \pm 0.71$ & $75.77 \pm 1.31$ & $73.16 \pm 0.95$ & $70.97 \pm 0.82$ \\
\hline FFT+FOS+SVM & $73.33 \pm 1.44$ & $96.31 \pm 0.22$ & $74.24 \pm 1.59$ & $74.16 \pm 2.05$ & $73.21 \pm 1.64$ & $69.86 \pm 1.89$ \\
\hline DCT+FOS+SVM & $69.36 \pm 0.95$ & $95.85 \pm 0.14$ & $71.02 \pm 1.01$ & $69.99 \pm 0.74$ & $68.87 \pm 0.93$ & $65.25 \pm 1.02$ \\
\hline DWT+FOS+SVM & $50.87 \pm 1.88$ & $93.13 \pm 0.25$ & $52.13 \pm 1.75$ & $53.52 \pm 2.29$ & $49.83 \pm 2.00$ & $44.64 \pm 2.25$ \\
\hline GLCM+SVM & $\mathbf{9 5 . 0 2 \pm 1 . 3 4}$ & $\mathbf{9 9 . 3 2 \pm 0 . 1 6}$ & $\mathbf{9 5 . 2 6} \pm 1.14$ & $\mathbf{9 5 . 0 8} \pm 1.14$ & $\mathbf{9 5 . 0 0 \pm 1 . 2 6}$ & $\mathbf{9 4 . 3 6} \pm 1.41$ \\
\hline GLRLM+SVM & $66.05 \pm 1.34$ & $95.27 \pm 0.18$ & $67.04 \pm 1.26$ & $67.32 \pm 1.32$ & $65.69 \pm 1.46$ & $61.62 \pm 1.54$ \\
\hline GLSZM+SVM & $88.74 \pm 1.64$ & $98.43 \pm 0.26$ & $89.06 \pm 1.84$ & $89.11 \pm 1.66$ & $88.72 \pm 1.94$ & $87.30 \pm 1.54$ \\
\hline
\end{tabular}

All metrics were computed in means and standard deviation. In Table 2, GLCM + SVM algorithm achieved the highest performance with $95.02 \pm 1.34 \%$ SEN, $99.32 \pm 0.16 \%$ SPE, $95.26 \pm 1.14 \%$ ACC, $95.08 \pm 1.14 \%$ PRE, $95.00 \pm 1.26 \%$ F1-Score and $94.36 \pm 1.41 \%$ MCC. The lowest performance belongs to the DWT + FOS + SVM model. The performance of this model is $50.87 \pm$ $1.88 \%$ SEN, $93.13 \pm 0.25 \%$ SPE, $52.13 \pm 1.75 \%$ ACC, $53.52 \pm 2.29 \%$ PRE, $49.83 \pm 2.00 \%$ F1 -Score and $44.64 \pm 2.25 \%$ MCC. Table 3 consists of GLCM+SVM metric performance for each folds. 
Table 3. GLCM+SVM Performance for Each Fold

\begin{tabular}{|c|c|c|c|c|}
\hline \multirow{2}{*}{$\begin{array}{c}\text { Evaluation } \\
\text { Metrics (\%) }\end{array}$} & \multicolumn{4}{|c|}{ 4-fold Cross Validation } \\
\cline { 2 - 5 } & Fold 1 & Fold 2 & Fold 3 & Fold 4 \\
\hline SEN & 93.01 & 95.68 & 95.50 & $\mathbf{9 5 . 8 7}$ \\
\hline SPE & 99.08 & 99.40 & 99.37 & $\mathbf{9 9 . 4 3}$ \\
\hline ACC & 93.56 & 95.83 & 95.64 & $\mathbf{9 6 . 0 2}$ \\
\hline PRE & 93.37 & 95.59 & 95.57 & $\mathbf{9 5 . 7 9}$ \\
\hline F1-Score & 93.10 & 95.60 & 95.52 & $\mathbf{9 5 . 7 8}$ \\
\hline MCC & 92.25 & 95.03 & 94.91 & $\mathbf{9 5 . 2 5}$ \\
\hline
\end{tabular}

Table 3 shows the cross validation performance of GLCM+SVM framework. It is seen that the highest performance is obtained Fold 4 using as validation. These metric values are observed as 95.87\% SEN, 99.43\% SPE, 96.02\% ACC, 95.79\% PRE, 95.78\% F1Score and 95.25\% MCC. The lowest performance belongs to Fold 1 data for validation is with 93.01\% SEN, 99.08\% SPE, 93.56\% ACC, 93.37\% PRE, 93.10\% F1-Score and 92.25\% MCC.

\section{Conclusions and Recommendations}

In this study, ATR framework from SAR images based on machine learning methods was proposed. SVM algorithm with Gaussian kernels is used after obtaining features with two different strategies from gray level SAR images. It can be seen that GLCM+SVM model is quite successful. It is obvious that gray level features extraction methods show higher performance compared to transformation and FOS features performed on the MSTAR dataset. In the scope of proposed framework, it has been proven that moving or stationary targets in SAR images can be detected successfully.

\section{References}

Dong, G., Kuang, G., Wang, N., Zhao, L., \& Lu, J. (2015). SAR target recognition via joint sparse representation of monogenic signal. IEEE Journal of Selected Topics in Applied Earth Observations and Remote Sensing, 8(7), 3316-3328.

Dong, G., Kuang, G., Wang, N., \& Wang, W. (2017). Classification via sparse representation of steerable wavelet frames on Grassmann manifold: Application to target recognition in SAR image. IEEE Transactions on Image Processing, 26(6), 28922904.

Eltoukhy, M. M., Faye, I., \& Samir, B. B. (2012). A statistical based feature extraction method for breast cancer diagnosis in digital mammogram using multiresolution representation. Computers in biology and medicine, 42(1), 123-128.

Gorovyi, I. M., \& Sharapov, D. S. (2017, June). Efficient object classification and recognition in SAR imagery. In 2017 18th International Radar Symposium (IRS) (pp. 1-7). IEEE.

Jianxiong, Z., Zhiguang, S., Xiao, C., \& Qiang, F. (2011). Automatic target recognition of SAR images based on global scattering center model. IEEE transactions on Geoscience and remote sensing, 49(10), 3713-3729.

Kulkarni, S. R., \& Harman, G. (2011). Statistical learning theory: a tutorial. Wiley Interdisciplinary Reviews: Computational Statistics, 3(6), 543-556.

Liu, H., \& Li, S. (2013). Decision fusion of sparse representation and support vector machine for SAR image target recognition. Neurocomputing, 113, 97-104.

Martone, A., Innocenti, R., \& Ranney, K. (2009). Moving target indication for transparent urban structures. US Army Research Laboratory Adelphi United States.

Novak, L. M., Owirka, G. J., \& Netishen, C. M. (1993). Performance of a high-resolution polarimetric SAR automatic target recognition system. Lincoln Laboratory Journal, 6(1).

Novak, L. M., Owirka, G. J., \& Brower, W. S. (1998, November). An efficient multi-target SAR ATR algorithm. In Conference Record of Thirty-Second Asilomar Conference on Signals, Systems and Computers (Cat. No. 98CH36284) (Vol. 1, pp. 3-13). IEEE.

Pan, Z., Qiu, X., Huang, Z., \& Lei, B. (2016). Airplane recognition in TerraSAR-X images via scatter cluster extraction and reweighted sparse representation. IEEE Geoscience and Remote Sensing Letters, 14(1), 112-116.

O'Sullivan, J. A., DeVore, M. D., Kedia, V., \& Miller, M. I. (2001). SAR ATR performance using a conditionally Gaussian model. IEEE Transactions on Aerospace and Electronic Systems, 37(1), 91-108.

Quan, S., Xiong, B., Xiang, D., \& Kuang, G. (2018). Derivation of the orientation parameters in built-up areas: With application to model-based decomposition. IEEE Transactions on Geoscience and Remote Sensing, 56(8), 4714-4730.

Singleton, R. C. (1968). Algorithms: Algorithm 338: algol procedures for the fast Fourier transform. Communications of the ACM, 11(11), 773-776.

Soh, L. K., \& Tsatsoulis, C. (1999). Texture analysis of SAR sea ice imagery using gray level co-occurrence matrices. IEEE Transactions on geoscience and remote sensing, 37(2), 780-795.

Solomon, C., \& Breckon, T. (2011). Fundamentals of Digital Image Processing: A practical approach with examples in Matlab. John Wiley \& Sons.

Thibault, G., Fertil, B., Navarro, C., Pereira, S., Cau, P., Levy, N., ... \& Mari, J. L. (2013). Shape and texture indexes application to cell nuclei classification. International Journal of Pattern Recognition and Artificial Intelligence, 27(01), 1357002. 